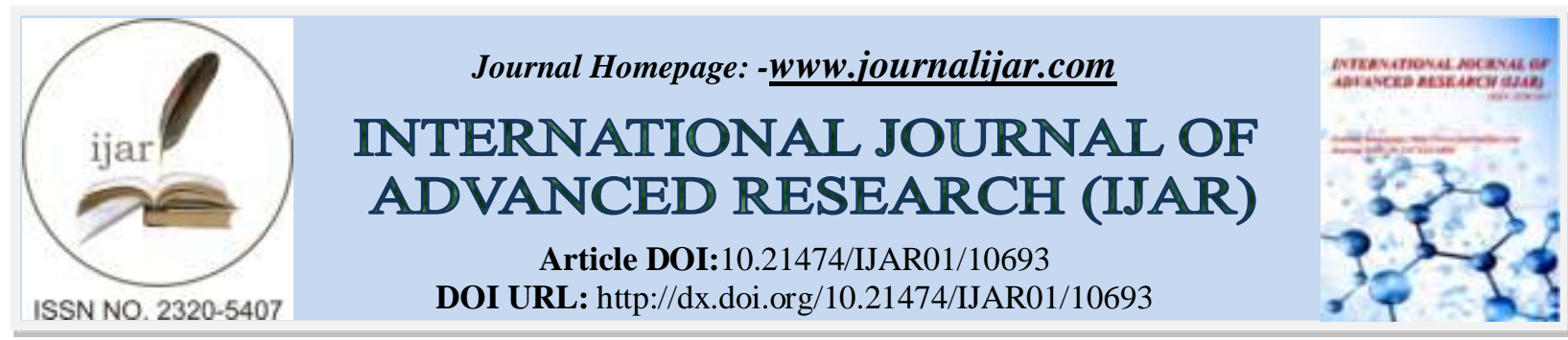

RESEARCH ARTICLE

\title{
ANTIMICROBIAL EFFECTS OF SILVER NANOPARTICLE USING VARIOUS INDIAN TRADITIONAL HERBS
}

Mr. Pankaj M. Chaudhari ${ }^{1}$, Mrs. Rupali B. Shimpi ${ }^{2}$ and Dr. P. H. Patil ${ }^{2}$

1. Department of Pharmacognosy, Kisan Vidya Prasarak Sanstha's, Institute of Pharmaceutical Education,Boradi, Shirpur, Dist- Dhule 425428.

2. Department of Pharmacology, Kisan Vidya Prasarak Sanstha's, Institute of PharmaceuticalEducation, Boradi, Shirpur, Dist- Dhule 425428.

\section{Manuscript Info}

Manuscript History

Received: 20 January 2020

Final Accepted: 22 February 2020

Published: March 2020

Key words:-

Nanoparticles, Antimicrobial, Silver Nanoparticles
Abstract

The field of nanotechnology is one of the most active areas of research in modern material science. Nanoparticles exhibit completely new or improved properties based on specific characteristics such as size, distribution and morphology.Herbal medicine is still the main stay of about $75-80 \%$ of the whole population, and the major part of traditional therapy involves the use of plant extract and their active constituents.New applications of nanoparticles and nano-materials are emerging rapidly. Silver is a well-known antimicrobial agent against a wide range of over 650 microorganisms from different classes such as gram-negative and gram-positive bacteria, fungi or viruses.More recently the metal is finding use in the form of silver nanoparticles. Silver nanoparticles are one of the metal nanoparticles have received significant consideration because they are effective antimicrobial agent/s that exhibits low toxicity. The aim of present study is to synthesize silver nanoparticles by using various extract, characterization of these silver nanoparticles \& Converts its gel formulation as well as to observe the antimicrobial activity.

Copy Right, IJAR, 2020,. All rights reserved.

\section{Introduction:-}

Herbal drugs are playing a vital role in health care system. This is because they are being cheap and locally available. The activity of herbal medicines depends on overall function of a variety of active components, as all the constituents provide synergistic action and thus enhance the therapeutic value (Shah CS and Qadry JS, 1998). Herbal medicines are now in great demand in the developing world for primary health care not because of inexpensive but also for better cultural acceptability, better compatibility with the human body and minimal side effects (Pal S et al., 2007).

The use of plants as the production assembly of silver nanoparticles has drawn attention, because of its rapid, ecofriendly, non-pathogenic, economical protocol and providing a single step technique for the biosynthetic processes. The reduction and stabilization of silver ions by combination of bio-molecules such as proteins, amino acids, enzymes, polysaccharides, alkaloids, tannins, phenolics, saponins, terpinoids and vitamins which are already established in the plant extracts having medicinal values and are environmental benign, yet chemically complex 
structures (Kulkarni N \&Muddapur, 2014).The protocol for the nanoparticle syntheses involves: the collection of the part of plant of interest from the available sites was done and then it was washed thoroughly twice/thrice with tap water to remove both epiphytes and necrotic plants; followed with sterile distilled water to remove associated debris if any. These; clean and fresh sources are shade-dried for 10-15 days and then powdered using domestic blender. For the plant broth preparation, around $10 \mathrm{~g}$ of the dried powder is boiled with $100 \mathrm{~mL}$ of deionized distilled water (hot percolation method). The resulting infusion is then filtered thoroughly until no insoluble material appeared in the broth. To $\mathrm{AgNO}_{3}$ solution, on addition of few $\mathrm{mL}$ of plant extract follow the reduction of pure $\mathrm{Ag}(\mathrm{I})$ ions to $\mathrm{Ag}(0)$ which can be monitored by measuring the UV-visible spectra of the solution at regular intervals (Sahayaraj K and Rajesh S, 2011).

The medical properties of silver have been known for over 2000 years. Silver is generally used in the nitrate form to induce antimicrobial effect but when silver nanoparticles are used, there is a huge increase in the surface area available for the microbes to be exposed to. Silver nanoparticles synthesized using plant extracts (from different sources) have been used for analysing their antimicrobial activities against different microbes (Ankanna Set al.,2010).

\section{Objective:-}

The objectives of present study is to synthesize silver nanoparticles by using herbals extract, characterization of these silver nanoparticles \& Converts its gel formulation as well as to observe the antimicrobial activity.

\section{Materials and Methods:- Collection of plant Material:}

Plant materials of Azadirachtaindica, Curcuma longa\&Ocimumsantumwere collected from Shirpur region of Dhule district (Maharashtra).

\section{Extraction Methodology:}

The extractions of powdered material were done by using Soxhlet apparatus.In solvent extraction, dried material is extracted with methanol. For extraction, $250 \mathrm{gm}$ of powdered material were packed in thimble containing filter paper and extracted with methanol in Soxhlet apparatus for the period till all the substances and others were extracted. The extract thus obtained was concentrated with the help of rotary vacuum evaporator.

\section{Synthesis of silver nanoparticles:}

For synthesis of silver nanoparticles, the conical flask containing $100 \mathrm{ml}$ of AgNO3 (1mM) was reacted with $12 \mathrm{ml}$ of themethanolic extract of A. indica, C. longa\&O. santum. This setup was incubated in dark (to minimize the photoactivation of silver nitrate), at $37^{\circ} \mathrm{C}$ under static condition (El-Nouret al., 2010).

\section{Preparation of gel formulation:}

$1 \mathrm{~g}$ of Carbopol 934 was dispersed in $50 \mathrm{ml}$ of distilled water with continuous stirring. $5 \mathrm{ml}$ of distilled water was taken and required quantity of methyl paraben and propyl paraben were dissolved by heating on water bath. Cool the solution, then to that added Propylene glycol 400. Further required quantity of SNPs was mixed to the above mixture and volume made up to $100 \mathrm{ml}$ by adding remaining distilled water. Finally full mixed ingredients were mixed properly to the Carbopol 934 gel with continuous stirring and triethanolamine was added drop wise to the formulation for adjustment of required skin $\mathrm{pH}(6.8-7)$ and to obtain the gel at required consistency. The same method was followed for preparation of all SNPs \& extract (Saeedet al., 2003; Das et al., 2011).

Experimental Requirements: (Sen and Batra, 2012; Zhao et al., 2010)

Equipments: Nichrome wire loop, Petri plates, Autoclave, Test tubes, Micropipette with number of tips. Borer (6 $\mathrm{mm}$ ), surgical cotton roll, Aseptic cabinet etc.

Chemicals: Dimethyl sulfoxide (DMSO), 70\% ethyl alcohol etc.

Media used for bacteria : Muller Hinton agar medium (Hi Media)

Inoculum size for bacteria: $1 \times 10^{8}$ bacteria $/ \mathrm{ml}$

Conc. ofstandard solution $\quad: 1 \mathrm{mg} / \mathrm{ml}$, prepared in dimethyl sulfoxide

Conc. of extracts $\quad: 1 \mathrm{mg} / \mathrm{ml}$, prepared in DMSO

Method used : Agar diffusion assay (Well size, 6mm) 
Evaluation of Antimicrobial activity by agar diffusion method (Dubey D., et al2012):

Procedure:

1. About $20 \mathrm{ml}$ of Muller Hinton agar medium for bacteria and Potato dextrose agar for fungi was allowed to set in empty sterile Petri plate.

2. About $0.1 \mathrm{ml}$ of fungal inoculums was made in petri plates preset for spore count, cell density and bacterial inoculums in respective Medias.

3. The well of $6 \mathrm{~mm}$ diameters were bored on the agar media using sterile borer and each plate was filled with 0.5 $\mathrm{ml}$ of plant extracts.

4. The plates containing bacteria were incubated at $37^{\circ} \mathrm{C}$ for 24 hours and those containing fungi were incubated at $30^{\circ} \mathrm{C}$ for 48 hours.

5. The positive antimicrobial activity was read by measuring zone of inhibition (in $\mathrm{mm}$ ) which was produced after incubation.

6. All the tests were repeated in triplicates.

\section{Result:-}

Evaluation of Gel Formulation:

Physical Evaluation:

Physical parameters such as Color and Appearance\& Homogeneity were checked.

\section{Measurement of pH:}

$\mathrm{pH}$ of the gel was measured by using $\mathrm{pH}$ meter.

Viscosity:

Viscosity of gel was measured by using Brookfield viscometer with spindle.

\section{Spreadibility:}

A sample of $0.5 \mathrm{~g}$ of each formula was pressed between two slides (divided into squares of $5 \mathrm{~mm}$ sides) and left for about 5 minutes where no more spreading was expected. Diameters of spreaded circles were measured in $\mathrm{cm}$ and were taken as comparative values for spreadability. The results obtained are average of three determinations.

\section{In vitro diffusion studies:}

The in vitro release of SNPs was carried out in phosphate buffer saline ( $\mathrm{pH}$ 5.5) using Cellophane dialysis membrane, Franz diffusion cell. The diffusion cells were thermo regulated with a water jacket. 0.5 gm gel of SNPs was loaded into dialysis membrane of donor compartment at it mounted on receptor compartment. Receptor compartment consist of $12.5 \mathrm{ml}$ of capacity fill with phosphate buffer saline $\left(\mathrm{pH} \mathrm{5.5)}\right.$ at maintain temperature $32^{\circ} \mathrm{C}$, which was constantly stirred at $200 \mathrm{rpm}$ with small magnetic bar. At the predetermined time intervals, samples were withdrawn from the receptor compartment, replaced with fresh medium in order to maintain sink conditions. The quantity of SNPs released was determined using UV spectro-photometry at $427 \mathrm{~nm}, 230 \mathrm{~nm} \& 210 \mathrm{~nm}$ for Tulsi SNP, Turmeric SNP \&Neem seed SNP respectively ( Saeedet al., 2003; Das et al., 2011).

\section{Drug Release Kinetics:}

To study the drug release kinetics, the data obtained from in vitro drug release study was fitted to various kinetic models such as zero order (Equation 4) as cumulative amount of drug released versus time; first-order (Equation 5) as $\log$ cumulative percentage of drug remaining versustime and Higuchi's model (Equation 6) as cumulative percentage of drug released versus square root of time.

\section{Antimicrobialactivity:}

SNPs \& extract of The Neem Seed, Turmeric \&Tulsiwere screened for antimicrobialactivity by agar-well diffusion method.

Table1:- Antimicrobial activity of SNPs \& Extract.

\begin{tabular}{|c|c|c|c|c|c|c|c|}
\hline \multirow{3}{*}{ Micro-organisms } & \multicolumn{7}{|c|}{ Diameter of Zone of inhibition(mm) } \\
\hline & \multicolumn{3}{|c|}{ Silver Nanoparticles } & \multicolumn{3}{|c|}{ Extract } & \multirow[t]{2}{*}{ Standard } \\
\hline & $\begin{array}{l}\text { Neem } \\
\text { Seed }\end{array}$ & Turmeric & Tulsi & $\begin{array}{l}\text { Neem } \\
\text { Seed }\end{array}$ & Turmeric & Tulsi & \\
\hline
\end{tabular}




\begin{tabular}{|c|c|c|c|c|c|c|c|}
\hline \multicolumn{8}{|l|}{ Gram Negative bacteria } \\
\hline $\begin{array}{l}\text { Pseudomonas } \\
\text { aeruginosa }\end{array}$ & 8.3 & 7.4 & 6.7 & 4.3 & 5.7 & 4.9 & 12.46 \\
\hline Escherichia coli & 6.5 & 7.9 & 8.8 & 3.7 & 4.9 & 5.1 & 29.12 \\
\hline \multicolumn{8}{|c|}{ Gram Positive bacteria } \\
\hline Staphylococcus aureus & 9.1 & 7.7 & 8.4 & 5.4 & 6.1 & 4.6 & 15.32 \\
\hline Bacillus subtilis & 7.5 & 6.6 & 7.9 & 4.9 & 3.9 & 4.4 & 18.02 \\
\hline \multicolumn{8}{|l|}{ Fungi } \\
\hline Candida albicans & 3.8 & 4.2 & 4.6 & 2.1 & 3.4 & 2.6 & 11.59 \\
\hline Aspergillusniger & 4.6 & 5.2 & 5.8 & 3.5 & 2.4 & 3.7 & 12.10 \\
\hline
\end{tabular}

Diameter in mm calculated by Vernier Caliper; '-' means no zone of inhibition; Well diameter= $6 \mathrm{~mm}$; NCIM-National Collection of Industrial Micro-organisms; Standard- Chloramphenicol

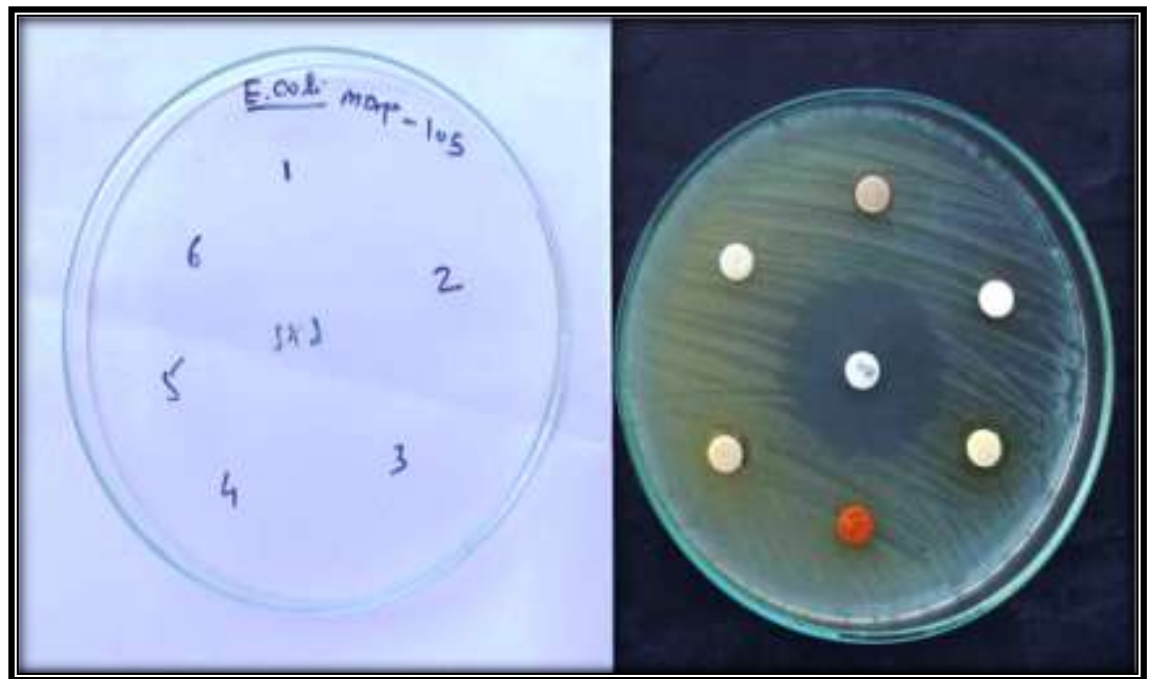

Figure 1:- Antimicrobial activity of SNPs\&Extract of Tulsi, Neem Seed \& Turmeric against: Escherichia coli.

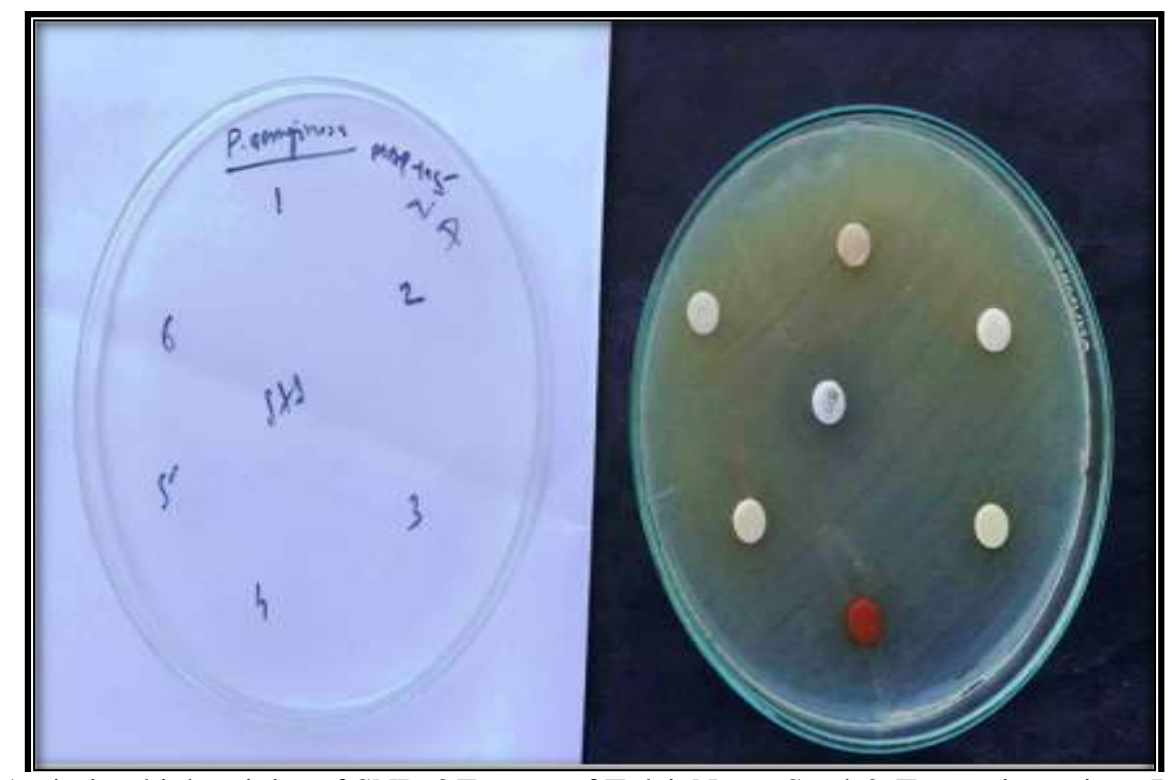

Figure 2:- Antimicrobial activity of SNPs\&Extract of Tulsi, Neem Seed \& Turmeric against: Pseudomonas aeruginosa. 


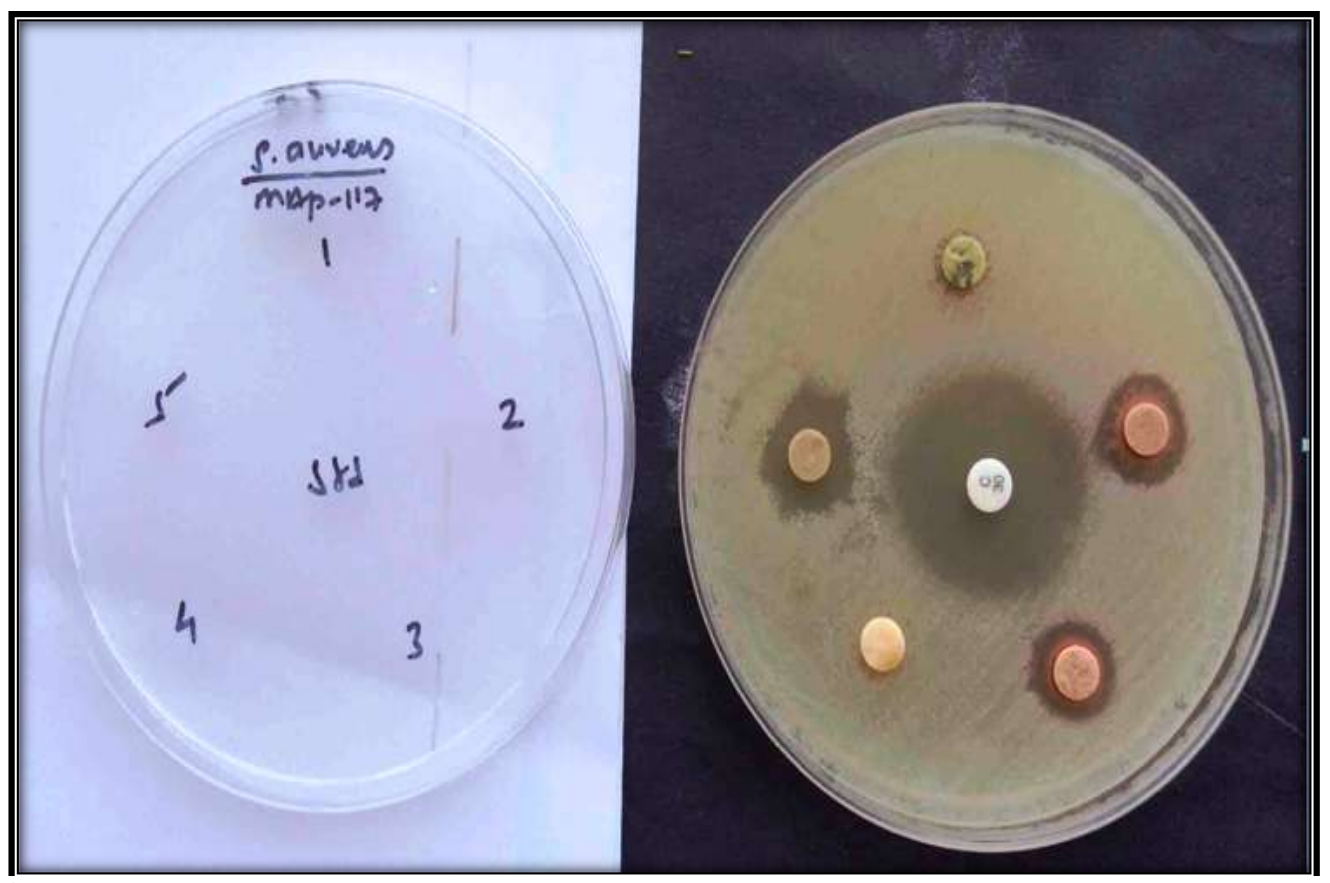

Figure 3:- Antimicrobial activity of SNPs\&Extract of Tulsi, Neem Seed \& Turmeric against: Staphylococcus aureus.

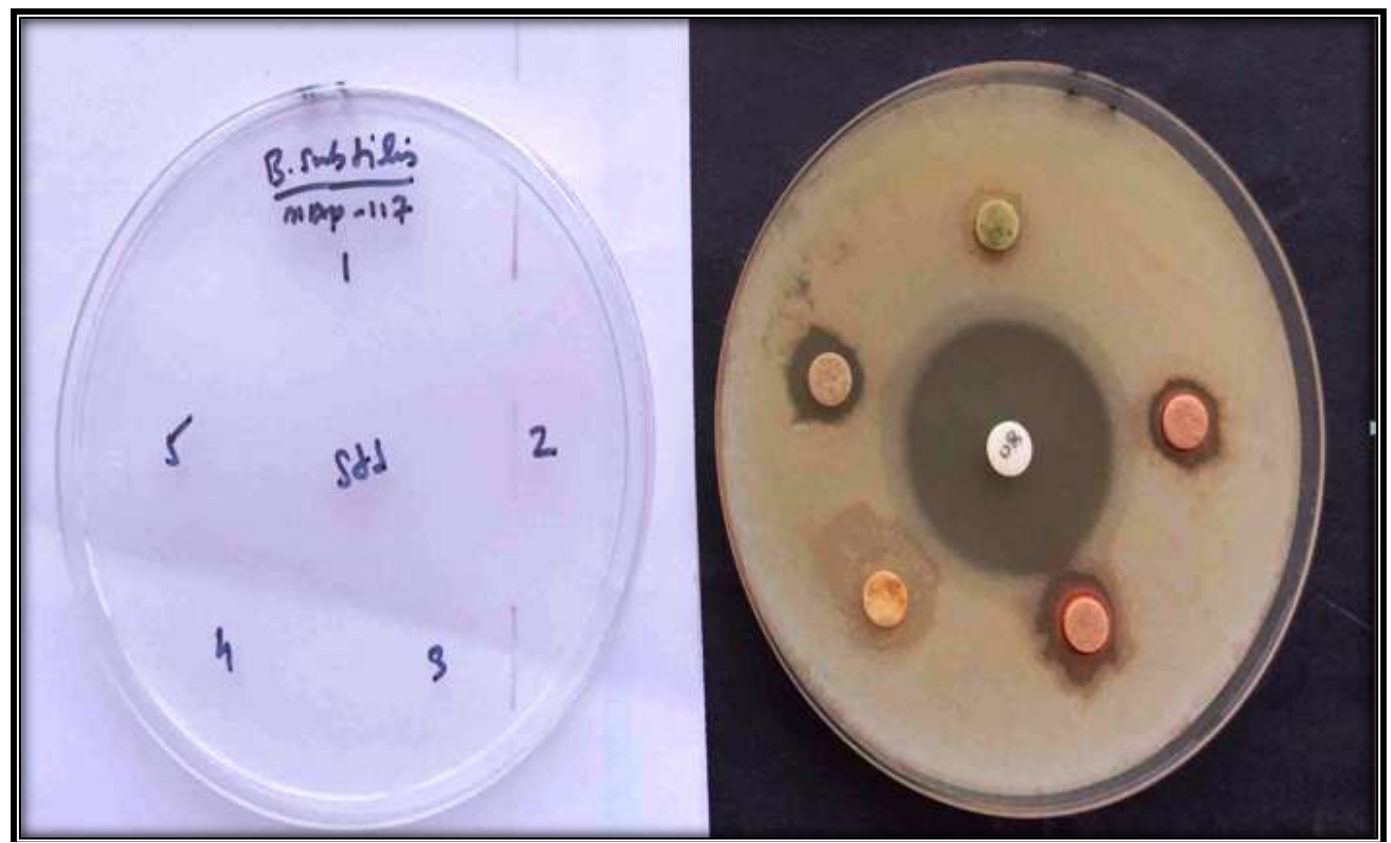

Figure 4:- Antimicrobial activity of SNPs\&Extract of Tulsi, Neem Seed \& Turmeric against: Bacillus subtilis

The antimicrobial activity of silver nanoparticles was evaluatedagainst Gram negative Escherichia coli \& Pseudomonas aeruginosaand Gram positive bacteria namely, Staphylococcus aureus\&Bacillus subtilis by disc method.The zone of inhibition of synthesized SNPs was found to be more than that of plant extract. Neem and Tulsi SNPs exhibited good antimicrobial activity against gram negative bacteria such as Escherichia coli \& Pseudomonas aeruginosawith zone of inhibition $8.3 \mathrm{~mm} \& 6.7 \mathrm{~mm}$ and $6.5 \mathrm{~mm} \& 8.8 \mathrm{~mm}$ respectively. Looking toward the activity of extracts Turmeric extract was most effective against Pseudomonas aeruginosa\&Tulsi extract gives positive effect against Escherichia coli.Neem and Tulsi SNPs exhibited good antimicrobial activity against gram positive bacteria such as Staphylococcus aureus\&Bacillus subtiliswith zone of inhibition $9.1 \mathrm{~mm} \& 8.4 \mathrm{~mm}$ and 7.5 
$\mathrm{mm} \& 7.9 \mathrm{~mm}$ respectively. Looking toward the activity of extracts Turmeric extract was most effective against Staphylococcus aureus\&Neem seed extract gives positive effect against Bacillus subtilis.

\section{Conclusion:-}

In the present study, dried powdered Tulsi leaves, Neem seeds \& Turmeric rhizomes were subjected to extraction with methanol. SNPs of all tree extract were prepared using standard method.

Since the antimicrobial effects of silver and its compounds are known from several years back, the antimicrobial activity of the synthesized silver nanoparticles was studied using the renowned agar well diffusion method. All SNPs were evaluated for its possible anti-microbial \& antifungal properties by standard in vitro models. The antibacterial efficacy was tested against the Gram negative bacteria namely, Pseudomonas aeruginosa\& Escherichia colias well as Gram positive bacteria namely, Staphylococcus aureus\&Bacillus subtilis. The results of antibacterial study suggest that the synthesized SNPs are very effective antibacterial agents. They exhibited very good activity against all tested bacterial strains.

In conclusion, it has been demonstrated that the extract of Tulsi leaves, Neem seeds \& Turmeric rhizomes are capable of producing Ag nanoparticles extracellularly and the Ag nanoparticles are quite stable in solution. The formed silver nanoparticles shows considerable antimicrobial \& antiseptic activity compared to the respective antibiotics. These biosynthesis silver nanoparticles prove to be potential candidates for medical applications where antimicrobialactivity is essential.

\section{References:-}

1. Ankanna, S., TNVKV, P., Elumalai, E. K., \&Savithramma, N. (2010). Production of biogenic silver nanoparticles using Boswelliaovalifoliolata stem bark. Dig J NanomaterBiostruct, 5(2), 369-372.

2. Das, S., Haldar, P. K., \&Pramanik, G. (2011). Formulation and evaluation of herbal gel containing Clerodendroninfortunatum leaves extract. International Journal of PharmTech Research, 3(1), 140-143.

3. Dubey, D., Sahu, M. C., Rath, S., Paty, B. P., Debata, N. K., \&Padhy, R. N. (2012). Antimicrobial activity of medicinal plants used by aborigines of Kalahandi, Orissa, India against multidrug resistant bacteria. Asian pacific journal of Tropical biomedicine, 2(2), 846-854.

4. El-Nour, K. M. A., Eftaiha, A. A., Al-Warthan, A., \&Ammar, R. A. (2010). Synthesis and applications of silver nanoparticles. Arabian journal of chemistry, 3(3), 135-140.

5. Shah CS and Qadry JS. (1998). A Text Book of Pharmacognosy, 216-220.

6. Pal, S., Tak, Y. K., \& Song, J. M. (2007). Does the antibacterial activity of silver nanoparticles depend on the shape of the nanoparticle? A study of the gram-negative bacterium Escherichia coli. Applied and environmental microbiology, 73(6), 1712-1720.

7. Kulkarni, N.,\&Muddapur, U. (2014). Biosynthesis of metal nanoparticles: a review. Journal of Nanotechnology, 216-220.

8. Sahayaraj, K., \& Rajesh, S. Bio nanoparticles: (2011). Synthesis and antimicrobial applications. Science against microbial pathogens: communicating current research and technological advances, 228-244.

9. Saeedi, M., MortezaSemnani, K., \&Ghoreishi, M. R. (2003). The treatment of atopic dermatitis with licorice gel. Journal of Dermatological Treatment, 14(3), 153-157.

10. Sen, A., \&Batra, A. (2012). Evaluation of antimicrobial activity of different solvent extracts of medicinal plant: Meliaazedarach L. Int J Curr Pharm Res, 4(2), 67-73.

11. Zhao, K., Penttinen, P., Guan, T., Xiao, J., Chen, Q., Xu, J. \&Strobel, G. A. (2011). The diversity and antimicrobial activity of endophytic actinomycetes isolated from medicinal plants in Panxi plateau, China. Current microbiology, 62(1), 182-190. 